\title{
Preliminary study on the estimation of the time of death in animals based on microflora development in a dog's gastrocnemius muscle
}

\author{
PIOTR LISTOS, MAGDALENA GRYZIŃSKA*, JUSTYNA BATKOWSKA*, \\ MAŁGORZATA DYLEWSKA*, EWA DUDZIŃSKA**, JACEK PIÓRKOWSKI
}

\author{
Department of Pathological Anatomy, Faculty of Veterinary Medicine, \\ University of Life Sciences in Lublin, Głęboka 30, 20-612 Lublin, Poland \\ *Department of Biological Basis of Animal Production, Faculty of Biology and Animal Breeding, \\ University of Life Sciences in Lublin, Akademicka 13, 20-950 Lublin, Poland \\ **Department of Public Health, Faculty of Health Sciences, \\ Medical University of Lublin, Lublin, W. Chodźki 1, 20-093 Lublin, Poland
}

Listos P., Gryzińska M., Batkowska J., Dylewska M., Dudzińska E., Piórkowski J.

Preliminary study on the estimation of the time of death in animals based on microflora development in a dog's gastrocnemius muscle

\section{Summary}

Determination of the exact time of death of a human being or animal is extremely important for investigations conducted by law enforcement agencies. The development of a single model of tests and analysis of the site of the incident would be a breakthrough for forensic and veterinary medicine in estimating the exact time of death. Microorganisms play a key role in the putrefaction process. Each stage of decomposition is characterized by the colonization of tissues by different microbial taxa. The objective of the study was to determine the suitability of microbiological tests for establishing the time of death, using the example of the gastrocnemius muscle in a dog (German Shepherd). The results of the study showed that sporulating aerobic bacteria of the species Bacillus cereus, as well as anaerobic bacteria, played a major role in the putrefaction process. No E. coli were found in the material. The first bacterial colonies belonging to the Bacillus cereus group were observed on the $7^{\text {th }}$ day after the death of the animal, and their quantitative growth persisted throughout the study period, i.e. until the $21^{\text {st }}$ day after death. The analysis carried out in this study shows that Bacillus cereus bacteria appear much sooner than anaerobic bacteria.

Keywords: veterinary forensics, putrefactive bacteria, carcasses decomposition

Examination of the microbiological flora of a carcass is one of the most important elements of forensic and veterinary medicine. The number of bacteria and the intensification of their growth indicate the time that has passed since the death (9). Abiotic factors such as temperature and humidity affect the growth and development of microbial flora. The decomposition process is initiated by aerobic bacteria using oxygen as a substrate for biochemical transformations. Once oxygen has been depleted, anaerobic bacteria begin to colonize the tissues. Most bacteria (96-99\%) involved in decomposition come from the external environment and from the organism itself (digestive system, respiratory system and skin). During microbiological decay under anaerobic conditions, gases are produced, such as ammonia and hydrogen sulphide, which give the carcass a characteristic putrid odour. The time elapsed since the death and environmental conditions at the site where the body is located have been shown to affect the composition of volatile substances released during the decomposition of mouse carcasses $(3,8)$.

Organic substances, including proteins, polysaccharides, and fats, are mainly composed of carbon dioxide, oxygen, and hydrogen. Trace amounts of sulphur, nitrogen and phosphates also occur, as well as minerals and trace elements: calcium, potassium, sodium, magnesium, iron, chlorine and copper. To degrade organic compounds, microbes need appropriate substances that are part of the cell wall, organelles, nucleic acids, proteins and polysaccharides. A suitable level of energy used in bacterial metabolism is required as well. Both of these conditions must be met to ensure 
Tab. 1. Bacteriological analyses

\begin{tabular}{|c|c|c|c|c|}
\hline Type of assay & Dilutions plated & Type of medium & $\begin{array}{c}\text { Incubation } \\
\text { temperature }\left[{ }^{\circ} \mathrm{C}\right]\end{array}$ & $\begin{array}{c}\text { Incubation time } \\
\text { [h] }\end{array}$ \\
\hline Total number of mesophilic aerobic bacteria & $1: 10 ; 1: 100 ; 1: 1,000 ; 1: 10,000 ; 1: 100,000$ & Plain agar & 30 & 72 \\
\hline E. coli bacteria & $1: 10 ; 1: 100 ; 1: 1,000 ; 1: 10,000$ & Endoless & 37 & 48 \\
\hline Number of anaerobic bacteria & $1: 10 ; 1: 100 ; 1: 1,000$ & TSC & 37 & 48 \\
\hline Number of Bacillus cereus spores & $1: 10 ; 1: 100 ; 1: 1,000$ & MYP & 30 & 72 \\
\hline
\end{tabular}

efficient degradation of organic compounds to simple inorganic compounds. Research continues on the further fate of somatic cells (14).

After circulation stops, cells become hypoxic, which results in the release of intracellular agents causing degradation of cellular organelles by autolytic enzymes. This results in the lysis of cell membranes, leading to the release of hydrocarbons, amino acids, lipids, mineral salts and water into the surrounding tissues. The elevated level of nutrients creates excellent living conditions for microorganisms. This causes a considerable increase in their numbers and in their replication rate per unit of time. A decrease in the availability of oxygen leads to anaerobic conditions, under which fermentation causes an increase in the concentration and release of gases, including hydrogen sulphate, carbon dioxide, methane, ammonia, sulphur dioxide and hydrogen. Detailed information is lacking on individual species of microorganisms taking part in these processes. In both humans and animals, most internal organs, such as the brain, liver, spleen and heart, are free of bacteria because the immune system maintains them in sterile conditions. After death, the immune system ceases to function, and microorganisms multiply in these organs. The process begins in the vicinity of the ileocecal valve, spreading to the liver and spleen, towards the heart, and finally to the brain. Bacteria colonize tissues through capillaries of the lymphatic and cardiovascular systems and through mucous membranes of the respiratory system (1).

The objective of the study was to determine the suitability of microbiological tests in establishing the time of death, using the example of a dog carcass.

\section{Material and methods}

The research material was a sample of tissue taken from the gastrocnemius muscle of a German Shepherd dog (male, black and tan hair colour, body weight $43 \mathrm{~kg}$, age - estimated by teeth examination - about 14 years). No pathological changes were observed in the animal when it was alive. From the moment of death until the material was collected, the carcass was kept in cold storage $\left(2-4^{\circ} \mathrm{C}\right)$. Seven days after the death of the dog, a sample of the gastrocnemius muscle was collected for analysis. The material was stored in a sterile container in the necropsy room at room temperature $\left(16-20^{\circ} \mathrm{C}\right)$ for 3 weeks. The sample weighed $5 \mathrm{~kg}$. Every 7 days, $20 \mathrm{~g}$ of muscle tissue was taken for bacteriological analysis. The testing was conducted for 3 weeks. The sample was kept in a sterile test tube. The bacteriological analysis included the total number of mesophilic aerobic bacteria in agar medium, the presence of E. coli bacteria in Endoless medium, the number of sporulating anaerobic bacteria (Clostridium perfringens) in TSC medium, and the number of Bacillus cereus in MYP agar. Cultures on microbiological media were conducted in at least two replications, and the bacterial count was expressed as the arithmetic mean of colony-forming units per $1 \mathrm{~g}$ of the sample (CFU/g) (Tab. 1). The results were log transformed, and statistical analysis was performed using the SPSS 20.0PL software package (6).

The total number of mesophilic aerobic bacteria was determined on eight Petri dishes. One $\mathrm{ml}$ each of material from $1: 10,1: 100$ and $1: 1,000$ dilutions was plated on two Petri dishes. After 72 hours, plates on which the number of colonies ranged from 30 to 300 were designated for further analysis. To determine the presence of E. coli bacteria, six Petri dishes were prepared. Streak plating was performed from $1: 10,1: 100$ and $1: 1,000$ dilutions. Gram staining was used to confirm the presence of $E$. coli. Six Petri dishes were used to determine the number of anaerobic bacteria (Clostridium perfringens). From $1: 10,1: 100,1: 1,000$ and $1: 10,000$ dilutions, $0.1 \mathrm{ml}$ each of material was plated and incubated under anaerobic conditions. To determine the number of Bacillus cereus bacteria, six Petri dishes were used, on which $0.1 \mathrm{ml}$ each of material was plated at dilutions of $1: 10,1: 100,1: 1,000$ and $1: 10,000$. Positive results were confirmed by culturing selected colonies on agar medium with ram's blood. After incubation $(24 \mathrm{~h}$ at $30^{\circ} \mathrm{C}$ ), the medium was checked for a colourless zone confirming the presence of Bacillus cereus.

\section{Results and discussion}

Fig. 1 presents the mean number of bacteria from two measurements, taking into account the dilutions used. E. coli bacteria on Endoless medium grew in the form of pink colonies with a metallic sheen. On TSC medium, anaerobic bacteria (Clostridium perfringens) grew in the form of black colonies. Bacillus cereus bacteria grew in the form of large pink colonies, usually surrounded by a zone of opacity.

On the $7^{\text {th }}$ day after death, the bacterial count per $1 \mathrm{~g}$ of material was calculated for plates on which the number of colonies ranged from 30 to 300 . In the case of the total bacterial count, this was the $1: 10$ dilution. Following the microbiological analysis of the number of Bacillus cereus, fewer than 30 colonies were observed on the plates from the lowest dilution. Moreover, no growth was noted in the case of $E$. coli or anaerobic bacteria. In both cases, the result was less than $1 \times 10$ bacteria per $1 \mathrm{~g}$ of material.

On the $14^{\text {th }}$ day after death, the total number of aerobic bacteria per $1 \mathrm{~g}$ of material was $1.29 \times 10^{6}$. 


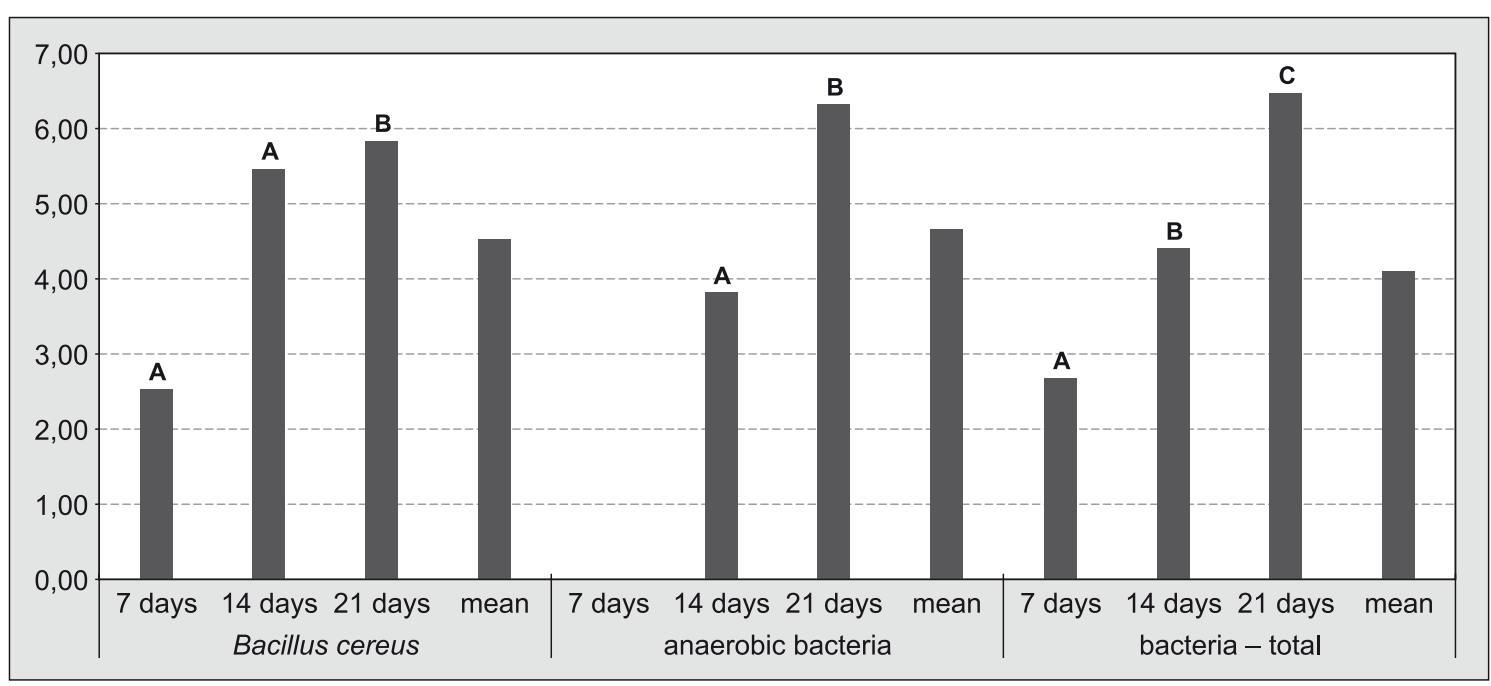

Fig. 1. Mean bacterial count in the gastrocnemius muscle group on days 7, 14 and 21 after death cultured in vitro on microbiological media. There is little information on the metabolic activity of microbes immediately after the death of an animal (5). In our study an increase in numbers of bacteria was observed in the post-mortem samples. Translocation of microorganisms from
The number of $E$. coli was less than $1 \times 10$ per $1 \mathrm{~g}$ of material. The number of anaerobic bacteria was $5.7 \times 10^{5} / \mathrm{g}$ of material. In the case of Bacillus cereus, $5.84 \times 10^{6} / \mathrm{g}$ of material were obtained.

On the 21th day after death, the total number of aerobic bacteria per $1 \mathrm{~g}$ of material was $5.87 \times 10^{6}$. The number of $E$. coli was less than $1 \times 10$ bacteria per $1 \mathrm{~g}$ of material. The number of anaerobic bacteria was $4.3 \times 10^{7} / \mathrm{g}$ of material, and the number of Bacillus cereus was $3.12 \times 10^{7} / \mathrm{g}$ of material.

The analysis of the results of the microbiological tests showed that sporulating aerobic bacteria of the species Bacillus cereus, as well as anaerobic bacteria, played a major role in the putrefaction process. No E. coli were found in the material. E. coli bacteria are not typical of putrefactive flora, but are among accompanying bacteria in the putrefaction process because of their proteolytic properties. Microbiological analysis indicates the colonization of tissues mainly by anaerobic bacteria from as early as the $14^{\text {th }}$ day until as late as the $21^{\text {st }}$ day after the animal's death. The first bacterial colonies belonging to the Bacillus cereus group were observed on the $7^{\text {th }}$ day after the death of the animal, and their quantitative growth continued throughout the study period, i.e. until the $21^{\text {st }}$ day after death. The analysis shows that Bacillus cereus bacteria appear much sooner than anaerobic bacteria.

The available literature describes many microbial species among those most frequently isolated from human and animal carcasses. These include Staphylococcus, Candida, Malassezia, Bacillus, Streptococcus, Micrococcus, E. coli, Klebsiella, Proteus, Serratia, Salmonella, Pseudomonas and Clostridium. Most of them are isolated from the intestines and respiratory tract, but many other bacterial species are involved in decomposition (15). For many years, research was directed towards the analysis of the metabolic level of microbes, mainly under laboratory conditions. Relatively little is known of the diversity of microorganisms, their level of metabolic activity in nature and their effect on the ecosystem. Only about $10 \%$ of bacterial species can be the surface of visible mucous membranes to the inside of the body after death leads to intensive growth of microorganisms in post-mortem samples (16). In the present study, anaerobic bacteria and Bacillus cereus were noted. In each period of the study, there was a considerable increase in the number of bacteria. Decomposition of the body begins immediately after death. Cellular enzymes, mainly proteases and lipases, are responsible for degradation of organic compounds. Microorganisms assimilate organic substances in order to produce energy for their own metabolism. The abundance of nutrients favours a rapid and intensive growth of microorganisms. Microbes are capable of degrading all organic substances both from human and animal remains, as well as from dead plant parts. Numerous sources report that complete decomposition takes place over a period of more than 10 years.

The composition of microorganisms is influenced by numerous factors, including the environment where the body is located. Decomposition of a carcass is a chemically, biochemically and geochemically complex process which directly affects the ecology of soil microbes. Traditional forensic examination focuses mainly on a macroscopic evaluation of post-mortem changes. Increasing attention is devoted to entomological testing, which deals with the colonization of the carcass by arthropods at various stages of decomposition (10, 13). However, there is an increasing awareness that microbes taking part in decomposition can potentially be used as evidence in criminal investigations. Decomposition of a body is a fundamental process that regulates ecosystem function and energy flow (4). The type and size of soil particles are among the most important factors influencing the rate of decomposition of a body buried in the ground. Research shows that by-products of decomposition cause the soil $\mathrm{pH}$ to change from initially alkaline to acidic. Decomposition of muscle tissue in an acidic environment is three times as fast as it is in an alkaline environment. Moreover, in sandy soil with a high moisture content and a high level of minerals, mainly calcium, phosphorus and manga- 
nese, mummification often takes place (4). Microbial diversity in the soil can be determined by one of two methods: by cell cultures or molecular biology techniques. In vitro culture makes it possible to identify about $10 \%$ of bacterial populations living in soil. As yet, no methods have been developed for culture of all bacterial taxa. Molecular biology methods make it possible to study the genetic code and other parameters characterizing a given species of microorganisms. However, testing by molecular biology techniques is extremely costly and time-consuming, and requires specialized laboratory equipment. Researchers from various fields of science are investigating new means of precisely determining the post-mortem interval. Thus far, despite enormous advances in science and technology, there is no single method of determining the exact time of a person's death that could be used by investigators. Scientists have developed a model, known as a microbial clock, that illustrates how microbiological testing of soil samples could be conducted. In the future this tool may find application in criminal investigations (4).

Little is known of the process of decomposition in carcasses immersed in seawater, and virtually nothing of the microbes involved in this process. It is commonly assumed that decomposition of remains in water differs from decomposition in the earth because of the large number of variables in aquatic environments. These include temperature, salinity, water depth, chemical composition, ocean currents, the nature of the basal substrate and the activity of microbes and scavengers. Unlike terrestrial environments, where the colonization of a carcass by arthropods (scavengers) at a specific number of hours, days and months after death can be predicted, there is no equivalent method for determining the time of death when the body is located in an aquatic environment. Over 40 years ago, water temperature was shown to be an important factor determining the advancement of decomposition. Several hundred human bodies recovered from a river were examined, and a table was created illustrating their decomposition at different water temperatures. The study did not clearly show whether it would be possible to estimate the time of death when a body has been immersed in water, but it did provide evidence that decomposition depends largely on temperature. Another factor determining the decomposition process is scavenger activity. Research on aquatic organisms is extremely difficult because of environmental conditions and technical limitations. Heterotrophic bacteria, ubiquitous in aquatic ecosystems, are responsible for ecological recycling of nutrients in the oceans (2).

An aquatic environment may be the site of suicide, homicide or mass disasters such as tsunamis. Depending on physicochemical factors, the body may be immersed or drift on the water surface. Sometimes, owing to the action of ocean currents, the body may undergo damage by hitting rocks or other obstacles.
Most studies on human remains in aquatic environments currently focus on the process of decomposition in different types of water, determination of the time interval from immersion, and the activity of insects, microbes and scavengers (7). In forensic investigations, determination of the time the body was immersed in water until its discovery is a key factor in discovering the truth about the circumstances and death of the victim. However, no method has as yet been found to reliably and definitively determine the time of death (12). Attempts have even been made to develop microbiological tests to diagnose drowning in both freshwater and saltwater (11).

A study on the development of bacteria in carcasses used the remains of pigs immersed in seawater during the autumn and winter. Four stages of decomposition were distinguished, i.e. the fresh carcass, early decay, advanced decay and skeletonization. Each of these four stages was marked by different characteristic features. No changes were observed in the first stage, and there were no visible signs of decomposition. At the stage of early decay, a characteristic odour was observed, as well as slight skin flaccidity and a thin mucilaginous film on the skin. The advanced stage of decay was characterized by a pronounced deterioration and fragmentation of soft tissues. In the next stage, the tissue became detached from the cranium, leading to partial skeletonization. The cranial bones displayed certain changes in colour in the form of reddening. After about 21 days, a complete skeletonization of parts of the pig could be seen. Scientists from New Zealand identified certain species of microbes, including bacteria of the genera Proteobacteria, Bacteroides, Firmicutes, Fusobacteria and Actinobacteria. Most genera of bacteria $(69 \%$ in the fall and $79 \%$ in the winter) colonized the remains at the same time (2).

Determination of the precise time of death of a person or animal is of crucial importance for investigations carried out by law enforcement agencies. The development of a single model of tests and analysis of the site of the incident would be a breakthrough for forensic and veterinary medicine in estimating the exact time of death. Microorganisms play a key role in the decomposition of the body by breaking down organic compounds. Each stage of decomposition is characterized by the colonization of tissues by different microbial species. Despite advanced technologies, new research methods and the efforts of qualified scientists, no single method has been developed for estimating the time of death. Microbiological analysis of remains may in the future become a key method for determining the post-mortem interval.

\section{References}

1. Can I., Javan G. T., Poxhitkov A. E., Noble P. A.: Distinctive thanatomicrobiome signatures found in the blood and internal organs of humans. J. Microb. Meth. 2014, 106, 1-7.

2.Dickson G. C., Poulter R. T., Maas E. W., Probert P. K., Kieser J. A.: Marine bacterial succession as a potential indicator of postmortem submersion interval. Forensic Sci. Int. 2009, 209, 1-10. 
3. Felsmann M. Z., Szarek J., Felsmann M., Babinska I.: Factors affecting temporary cavity generation during gunshot wound formation in animals - new aspects in the light of flow mechanics: a review. Vet. Med-Czech. 2012, 57, 569-574.

4. Finley S. J., Benbow M. E., Javan G. T.: Potential applications of soil microbial ecology and next-generation sequencing in criminal investigations. Appl. Soil Ecol. 2015, 88, 69-78.

5. Howard G. T., Duos B., Watson-Horzelski E. J.: Characterization of the soil microbial community associated with the decomposition of a swine carcass. Int. Biodeter. Biodegr. 2010, 64, 300-304.

6. IBM Corp. Released 2011. IBM SPSS Statistics for Windows, Version 20.0 Armonk, NY, IBM Corp.

7. Kakizaki E., Kozawa S., Matsuda H., Muraoka E., Uchiyama T., Sakai M. Yukawa N.: Freshwater bacterioplankton cultured from liver, kidney and lungs of a decomposed cadaver retrieved from a sandy seashore: Possibility of drowning in a river and then floating out to sea. Legal Medicine 2010, 12, 195-199.

8. Kasper J., Mumm R., Ruther J.: The composition of carcass volatile profiles in relation to storage time and climate conditions. Forensic Sci. Int. 2012, 223, 64-71.

9. Lehman D. C.: Forensic Microbiology. Clin. Microbiol. Newslett. 2014, 36, 49-54.
10. Listos P., Gryzinska M., Kowalczyk M.: Analysis of cases of forensic veterinary opinions produced in a research and teaching unit. J. Forensic Legal Med. 2015, 36, 84-89.

11. Lucci A., Campobasso C. P., Cirnelli A., Lorenzini G.: A promising microbiological test for the diagnosis of drowning. Forensic Sci. Int. 2008, 182, 20-26.

12. Magni P. A., Venn C., Aquila I., Pepe F., Ricci P., Di Nunzio C., Ausania F., Dadour I. R.: Evaluation of the floating time of a corpse found in a marine environment using the barnacle Lepas anatifera L. (Crustacea: Cirripedia: Pedunculata). Forensic Sci. Int.2015, 247, e6-e10.

13. Nozdryn-Płotnicki Z., Listos P., Łopuszyński W., Dębiak P.: Section investigation of animals wounded from fire arms: some remarks. Med. Weter. 2005, 61, 887-889.

14. Schoenen D., Schoenen H.: Adipocere formation - The result of insufficient microbial degradation. Forensic Sci. Int. 2013, 226, 301.e1-301.e6.

15. Vass A. A.: Beyond the grave - understanding human decomposition. Microbiology Today 2001, 28, 190-193.

16. Weber M. A., Hartley J. C., Brooke I., Lock P. E., Klein N. J., Malone M., Sebire N. J.: Postmortem interval and bacteriological culture yield in sudden unexpected death in infancy (SUDI). Forensic Sci. Int. 2010, 198, 121-125.

Corresponding author: Dr Piotr Listos, PhD, Department of Pathological Anatomy, University of Life Sciences in Lublin, Glęboka 30, 20-612 Lublin, Poland; e-mail: piotr.listos@up.lublin.pl 